\title{
Avaliação da Educação Ambiental em escolas vinculadas a uma usina de cana-de-açúcar na Mata Sul de Pernambuco
}

\author{
Igor Vinícius Pereira Cunha ${ }^{1}$ \\ Maria Juliana Gomes Arandas ${ }^{2}$ \\ Janaina Kelli Gomes Arandas ${ }^{3}$ \\ Eveline de Cássia Batista de Almeida Alves ${ }^{1}$ \\ Ilka Dayane Duarte de Sousa ${ }^{2}$ \\ Suellen Maria Silva Dias ${ }^{4}$ \\ Katharine Raquel Pereira dos Santos ${ }^{1 *}$

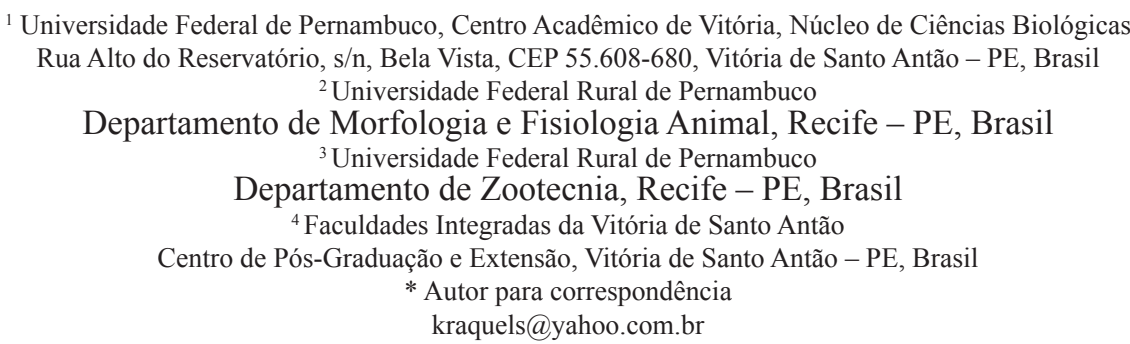

Submetido em 30/11/2012

Aceito para publicação em 23/06/2013

\section{Resumo}

A Educação Ambiental (EA) no Brasil sofreu um crescimento recente e acelerado guiado pelo avanço da consciência ambiental. A educação formal incorporou essa temática para formar cidadãos atuantes em questões ambientais de forma consciente e sustentável. Uma escola influencia a comunidade onde atua e a EA é um dos caminhos para tentar superar problemas ambientais. As escolas estudadas estão localizadas em área de Mata Atlântica, com parte de seus remanescentes situada em propriedades das usinas de cana-de-açúcar. Portanto, o artigo objetiva analisar a inclusão da EA em escolas vinculadas à Usina Trapiche, investigando, por meio de questionários, a percepção dos professores sobre o tema nos locais de trabalho e suas dificuldades para abordar os conteúdos. Os questionários foram respondidos por 22 professores que atendem aproximadamente 1.300 alunos nas escolas estudadas. Todas essas escolas realizam atividades de EA, com predominância da questão acerca dos resíduos sólidos. As dificuldades relatadas foram comuns à Educação em geral. Foi constatado que a EA está inserida no contexto estudado, mas o desafio parece ser incluí-la definitivamente no currículo e no dia a dia da escola. Além da pesquisa, foram realizadas atividades lúdicas, oficinas e palestras, vivenciando com a comunidade escolar os temas mais relevantes da EA na região.

Palavras-chave: Educação Ambiental; Educação formal; Formação de professores; Projetos pedagógicos 


\section{Abstract}

Evaluation of Environmental Education in schools linked to a cane sugar mill in the South Forest of Pernambuco. Environmental Education (EE) in Brazil has recently undergone an accelerated growth driven by the advancement of environmental awareness. Formal education has incorporated this theme in order to train citizens actively concerned with environmental issues in a conscious and sustainable way. A school influences the community where it operates and $\mathrm{EE}$ is one of the routes to try overcoming environmental problems. The schools under study are located in an Atlantic forest area, and part of these remnants is within properties of cane sugar mills. Therefore, this paper aims to analyze the inclusion of EE in schools linked to Usina Trapiche, investigating, through questionnaires, the perception of teachers on the theme at workplaces and their difficulties for addressing contents. The questionnaires were answered by 22 teachers serving about 1,300 students at the schools under study. All these schools perform EE activities, with a predominance of the solid waste issue. The difficulties reported were common to Education in general. One observed that EE is included within the studied context, but the challenge seems to be definitely including it in the syllabus and the school's everyday life. In addition to the research, playful activities, workshops, and lectures were conducted, experiencing along with the school community the most relevant EE themes in the region.

Key words: Environmental Education; Formal education; Pedagogical projects; Teacher training

\section{Introdução}

No Brasil, a discussão sobre a inserção da Educação Ambiental (EA) no ensino ganhou projeção a partir da década de 80, e já em 1994 foi elaborado o primeiro Programa Nacional de Educação Ambiental ${ }^{1}$. Desde então houve o que Loureiro (2008) chamou de "uma crescente requalificação da compreensão e do modo de nos relacionarmos na natureza" ou o que Carvalho (2008) chamou de "avanço da consciência ambiental".

Essa recente mudança é possivelmente responsável pela expansão observada da EA no Brasil nos últimos anos. Segundo Veiga et al. (2005), de 2001 para 2004 houve uma taxa de crescimento de $32 \%$ no número de escolas que, de alguma forma (projetos, disciplinas, etc.), oferecem EA. Biondo et al. (2010) indicaram que entre os anos de 2006 e 2007 91\% dos docentes entrevistados desenvolveram projetos de EA.

O Art. 2 da Lei das Diretrizes e Bases (LDB) estabelece como finalidade da educação o pleno desenvolvimento do educando, seu preparo para o exercício da cidadania e sua qualificação para o trabalho; o Art. 14 das Diretrizes Curriculares Nacionais (DCN)

\footnotetext{
Programa Nacional de Educação Ambiental - PRONEA: Programa instituído em 1994 de forma compartilhada entre o Ministério do Meio Ambiente e o Ministério da Educação e do Desporto e previa a capacitação de gestores e educadores, desenvolvimento de ações educativas e desenvolvimento de instrumentos e metodologias.
}

para a educação básica aponta o "conhecimento do mundo físico e natural" como um dos integrantes da base nacional comum para a educação básica; e nos Parâmetros Curriculares Nacionais (PCN's) o tema "Meio Ambiente" é proposto como um dos temas transversais a serem trabalhados nas escolas, indicando que essa temática passaria a não ser mais algo restrito às disciplinas que abordam as Ciências Naturais (BIZERRIL; FARIA, 2001). Portanto, a EA deve ter uma grande importância nessa formação complexa do cidadão que possa ser realizado não para absorver uma grande quantidade de conteúdo, mas para construção de conhecimento de forma que possa atuar na sociedade, numa construção histórica e coletiva da humanidade, considerando a indissociabilidade entre o social e o ecológico (CARVALHO, 2001; 2008; LOUREIRO, 2004; 2008; GUERRA; GUIMARÃES, 2007; TOZONIREIS, 2008; BIONDO et al., 2010).

Entretanto, os professores têm encontrado muitas dificuldades em desenvolver a EA dentro dessas novas demandas, o que é comumente associado a uma deficiente formação profissional dos professores, mas que também pode envolver problemas não relacionados com recursos humanos. Tem sido muito difícil tratar essa temática de forma interdisciplinar por que: 1) ainda é muito forte a ideia cartesiana de divisão dos conteúdos em disciplinas; 2) a inserção da EA é relativamente recente; 3) os professores não se sentem seguros para 
aderir a determinados projetos; e 4) pelo fato da EA se encontrar ainda pouco enraizada institucionalmente no espaço acadêmico. A presença da EA no contexto escolar é transmitida de forma fragmentada através de ações pontuais, sem ainda se converter em práticas pedagógicas do cotidiano, por isso, em alguns casos temos a falsa impressão de que a EA está presente. Sem contar que a mesma também está sujeita aos problemas comuns da educação em geral, como a persistência do modelo tradicionalista do ensino na transmissão dos conteúdos (BIZERRIL; FARIA, 2001; JACOBI, 2004; GUERRA; GUIMARÃES, 2007; TOZONI-REIS, 2008; BIONDO et al., 2010).

Além da importância da EA para a formação do cidadão, acredita-se que ela é um dos principais caminhos para tentar superar os problemas ambientais (LIMA, 1999; CARVALHO, 2001; JACOBI, 2004; LOUREIRO, 2004; EFFTING, 2007). A educação é tão necessária para a preservação ambiental que a Constituição Federal, em seu Art. 225, fala do dever de defender e proteger "o meio ambiente ecologicamente equilibrado para presentes e futuras gerações", por meio da promoção da EA. A escola tem um poder de influenciar e transformar a comunidade na qual está inserida (VEIGA et al., 2005; LOUREIRO et al., 2006). Nessa perspectiva, também é de suma importância que haja cada vez mais a integração das ações pedagógicas com as ações ecológicas e que seja estimulada a inserção da EA na escola com a preocupação de uma contextualização dos sujeitos das escolas no seu entorno histórico, social e natural (CARVALHO, 2001; EFFTING, 2007).

As escolas que foram nosso objeto de estudo estão situadas em área de Mata Atlântica. Nela habita a maioria das espécies oficialmente ameaçadas de extinção no Brasil (TABARELLI et al., 2005). Este bioma é considerado um dos "hotspots" mundiais, sendo uma das áreas mais abundantes em biodiversidade, com elevada concentração de espécies endêmicas e mais ameaçadas do Planeta (GALINDO LEAL; CÂMARA, 2005). Atualmente, restam somente $7,8 \%$ dessa floresta original (CAMPANILI; PROCHNOW, 2006) e a situação é ainda mais crítica na sua porção nordestina, que é uma das áreas mais ameaçadas (BROOKS; RYLANDS, 2005), com $2 \%$ de remanescente em arquipélagos de pequenos fragmentos florestais, inseridos em uma matriz de plantações de cana-de-açúcar e pastagens (VIANA et al., 1997; RANTA et al., 1998; SILVA; TABARELLI, 2000).

Apesar dessa grave situação, muito pouco tem sido feito para a conservação deste bioma, e os últimos remanescentes de floresta ainda encontram-se sob intensa pressão antrópica e risco iminente de extinções. Grande parte do remanescente da Mata Atlântica situada acima do rio São Francisco está situado em propriedades das usinas de cana-de-açúcar (MORELLATO; HADDAD, 2000; UCHOA-NETO; TABARELLI, 2002). Então, não se pode pensar na preservação do Bioma Floresta Atlântica e no desenvolvimento da EA em Pernambuco sem estudos específicos da situação atual das escolas que estão inseridas nessa realidade.

Dentro desse contexto, esta pesquisa verificou como está inserida a EA em escolas mantidas pela Usina Trapiche, que desenvolve alguns projetos de conservação como: a regeneração da mata ciliar, o projeto das capivaras, piscicultura e apiário, reciclagem do lixo doméstico e o desenvolvimento de hortas educativas, investigando como a EA é desenvolvida nas escolas e as dificuldades dos mesmos para lidar com esses conteúdos. Por conseguinte/consequência, foram desenvolvidas atividades com esses professores, integrando a universidade com as escolas, na tentativa de colaborar com o desenvolvimento da EA na região.

\section{Material e Métodos}

\section{Área de estudo}

A Usina Trapiche está localizada em Sirinhaém, no litoral sul no estado de Pernambuco, a aproximadamente $76,5 \mathrm{~km}$ de sua capital, Recife. Esta usina de cana-deaçúcar possui aproximadamente oito mil hectares de área preservada. Destes, cerca de cinco mil hectares de Mata Atlântica inseridos em uma matriz composta por pastos, plantações de cana-de-açúcar, frutos e leguminosas. Neste local, a Usina Trapiche, dentro de seu espaço, mantém cinco escolas (Grupo Escolar Dona Neném, Escola Nossa Senhora das Graças, Escola São José, Escola Santo Antônio e Escola Santa Ana) que atendem cerca de 1300 alunos, desde a Educação Infantil 
às séries iniciais do Ensino Fundamental, e contam com 22 professores vinculados à Usina, que trabalham em regime integral.

\section{Coleta de dados}

Foram aplicados 22 questionários direcionados para todos os professores que compõem o corpo docente, com o intuito de verificar, quantitativamente, como a EA está inserida nas cinco escolas localizadas no espaço da Usina Trapiche. A coleta de dados, a partir das respostas dos docentes, se deu através da distribuição de questionários impressos que continham tanto questões abertas quanto de múltipla escolha. A maioria delas foi aberta, para as perguntas que poderiam mais possibilidades de respostas, e estas foram avaliadas e agrupadas pelo significado, ou, melhor dizendo, pela proximidade entre os diversos termos usados. As perguntas eram sobre os tópicos relacionados abaixo:

- Tempo de ensino dos docentes;

- Abordagem da EA no contexto escolar;

- Atividades de campo realizadas com os alunos;

- Presença, nas escolas, de projetos que incluem a EA;

- Dificuldades enfrentadas nas aulas que incluem a EA;
- Disponibilidade de materiais sobre a Mata Atlântica e seus ecossistemas associados;

- Orientações para a comunidade acerca de biodiversidade e seu uso sustentável.

\section{Resultados e Discussão}

Todos os professores das escolas estudadas são do sexo feminino e de caráter polivalente, ou seja, lecionam todas as disciplinas da matriz curricular do $1^{\circ} \underline{\mathrm{o}}$ ao $5^{\underline{0}}$ ano do ensino fundamental. E a maioria dessas professoras $(63,63 \%)$ possui mais de 10 anos de atividade docente, algo semelhante ao descrito por Biondo et al. (2010), que em seu estudo com professores no Estado do Rio Grande do Sul também constatou que a maioria deles estava há mais de 10 anos na profissão, e relacionou isso a uma possível dificuldade dos professores mais antigos de entender os conceitos incorporados mais recentemente à educação.

Quanto aos temas relacionados à EA abordados no contexto escolar, o tópico resíduos sólidos foi o mais frequente nas respostas dos entrevistados, totalizando $28,6 \%$ (Figura 1), seguido por desmatamento, com $25 \%$ de incidência. A poluição constituiu $19,7 \%$, enquanto a preservação ambiental compreendeu $14,1 \%$ das respostas dos entrevistados. $\mathrm{O}$ aquecimento global

FIGURA 1: Temas sobre Educação Ambiental abordados nas escolas de Educação Infantil e/ou Ensino Fundamental localizadas na Usina Trapiche (Sirinhaém/PE).

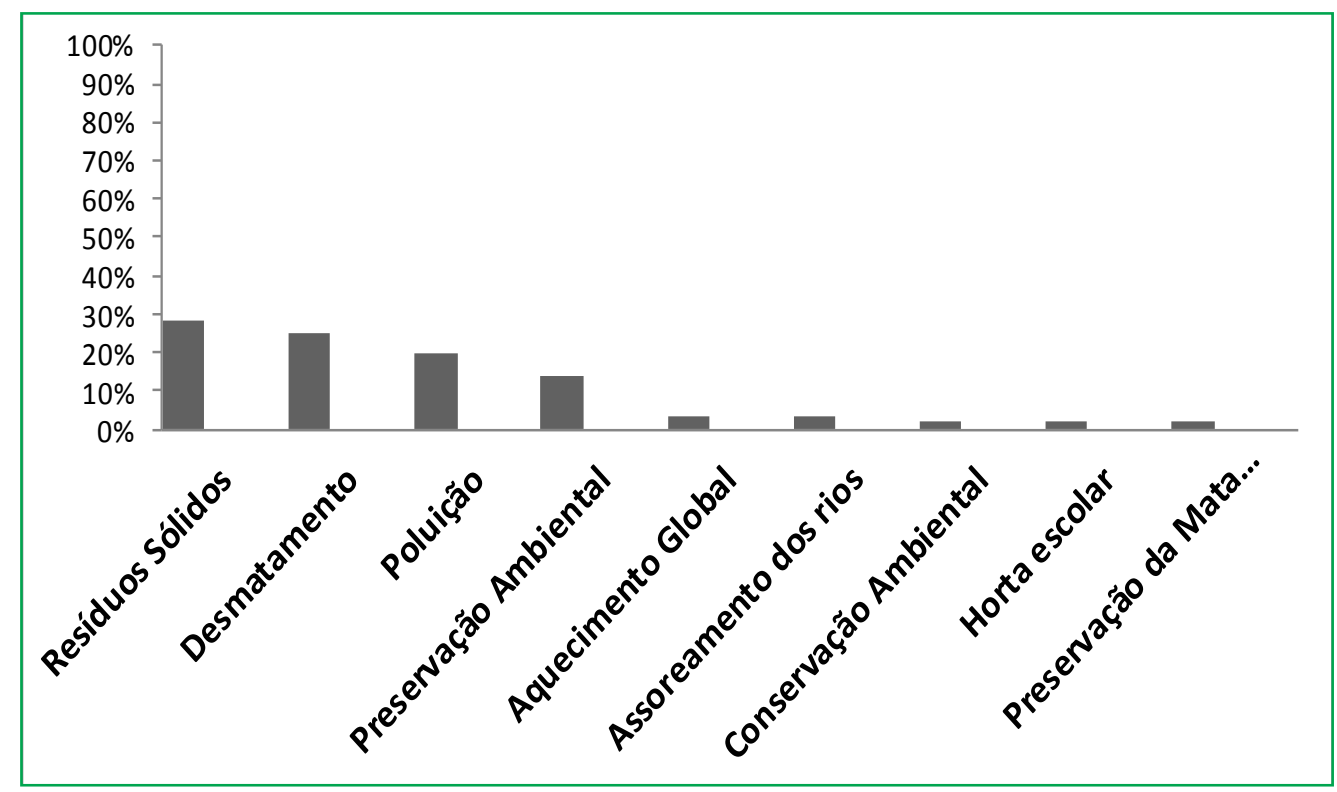


e o assoreamento dos rios representaram 3,6\% das respostas. Os temas menos abordados, de acordo com os professores, foram: preservação ambiental, horta escolar e preservação da Mata Atlântica. Cada um representa o percentual de 1,8\%. De acordo com Loureiro et al. (2006), em uma análise nacional da EA no Brasil, o tema "água" foi o mais trabalhado nos projetos e o tema "lixo" aparece em segundo junto com "reciclagem". Entretanto, Biondo et al. (2010), por exemplo, observou que o tema lixo também foi o mais recorrente $(87,2 \%)$, por ser um assunto de fácil desenvolvimento. As variações encontradas de uma região para a outra, ou de nível nacional para um nível regional, podem estar relacionadas aos diferentes contextos. Alguns problemas podem ter mais ênfase em um determinado município, sendo isso refletido na atividade escolar.

A maioria dos professores (72\%) respondeu que realizam atividades de campo voltadas para a EA com os seus alunos. Destes, $40 \%$ já executaram ações voltados à coleta de lixo nas escolas. Em seguida, os passeios ecológicos foram apontados como a segunda atividade de campo mais realizada pelos docentes, com um total correspondente a $30 \%$. A terceira atividade mais citada foi a horta escolar, totalizando $25 \%$ das respostas. Finalmente, a quarta atividade mencionada pelas professoras, foi a Mata Ciliar, numa referência ao projeto de recuperação da mata ciliar desenvolvido pela usina, que apresentou o percentual de $5 \%$ (Figura 2). Esses resultados diferem do estudo de Bezerra et al. (2008) que identificaram que a maioria dos professores $(53 \%)$ de escolas próximas a uma Unidade de Conservação na Região Metropolitana do Recife alegou nunca ter realizado atividade extra classe ou de campo. Essa diferença pode indicar que o contexto aqui apresentado possa ter uma EA mais preocupada em diversificar os tempos e os espaços pedagógicos, aproveitando as oportunidades de relacionar a teoria com a prática. A EA abrange diversas áreas, por isso, pode ser trabalhada nos mais variados contextos, dentre eles, a realização de atividades em áreas que permitem o contato direto com o ambiente é uma estratégia de grande importância, pois permite a sensibilização sobre os problemas ambientais e uma abordagem menos fragmentada do conhecimento ecológico (SENICIATO; CAVASSAN, 2004; DOURADO, 2006). Além disso, surgem oportunidades de reflexão sobre valores, imprescindíveis às mudanças comportamentais e, sobretudo, atitudinais (CARVALHO, 1998).

Todas as escolas localizadas no espaço da usina desenvolvem projetos de EA, principalmente aqueles voltados para a horta escolar e o lixo doméstico. Há uma tendência de que cada vez mais escolas desenvolvam a EA e que cada vez mais alunos tenham acesso a ela.

FIGURA 2: Atividades de Educação Ambiental realizadas pelos professores nas escolas de Educação Infantil e/ou Ensino Fundamental localizadas na Usina Trapiche (Sirinhaém/PE).

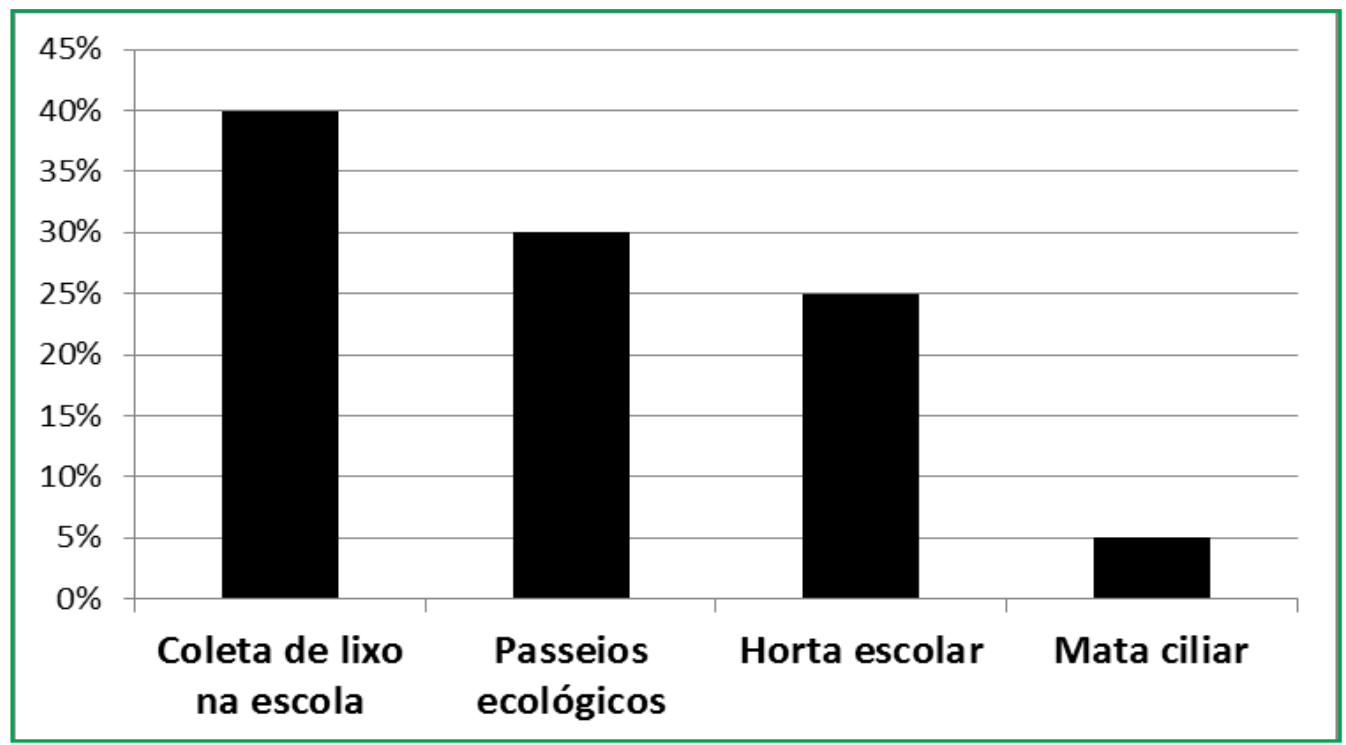


Veiga et al. (2005) mostrou o crescimento acelerado da EA no Ensino Fundamental no Brasil entre 2001 e 2004 e os estados do Norte e Nordeste, que estavam com muita desvantagem em relação aos outros, como no caso de Pernambuco, tiveram um maior crescimento de forma que as taxas de cobertura da EA ficassem igualmente altas em todo o Brasil. Este estudo demonstrou também que a modalidade de aplicação da EA na forma de projetos teve um crescimento muito elevado, com destaque para a Região Nordeste.

Os projetos pedagógicos permitem que os temas sejam vivenciados de maneira interdisciplinar, de modo que os alunos descubram as relações existentes entre as diversas áreas do conhecimento, construindo uma ponte entre as informações obtidas nas aulas à sua realidade. Essas atividades vão além dos conteúdos programáticos, tornando a aprendizagem mais significativa, aplicada e relevante para os alunos (HERNÁNDEZ; VENTURA, 1998; KRASILCHIK; MARANDINO, 2004; SANTOS, 2008).

Além dos projetos desenvolvidos pelas escolas desse estudo são também conhecidos projetos locais de conservação e o desenvolvimento de pesquisas, através de convênio entre a Universidade Federal de Pernambuco e a Usina Trapiche. Todos esses fatores formam um contexto bem favorável tanto para que os projetos de conservação possam contar com a influência das escolas como para que as escolas enriqueçam suas atividades e possam desenvolver a EA para a formação de cidadãos. Apesar de todas essas possibilidades, a interação entre os projetos educacionais e ambientais ainda é limitada, pois dentre as atividades citadas pelos professores nenhuma está relacionada à participação efetiva da escola na gestão ambiental sugerida em Quintas (2004). Só não sabemos ainda se esse fato se deve a pouca idade dos alunos, ao despreparo dos professores ou à falta de autonomia da escola diante dos outros projetos.

Quanto às dificuldades enfrentadas nas aulas que envolvem EA, a conscientização dos alunos (40,9\%) aparece como principal impedimento, semelhante ao observado por Biondo et al. (2010). Em seguida, apareceu a falta de recursos $(13,6 \%)$, de tempo $(13,6 \%)$ e de orientação dos pais $(13,6 \%)$. Em menor proporção, foram relatados: a falta de aulas de campo $(4,6 \%)$, o trabalho de arte com a reciclagem $(4,6 \%)$, a necessidade de mais conhecimentos $(4,6 \%)$ e o trabalho de feiras de ciências (4,5\%) (Figura 3). Já em Loureiro et al. (2006), em âmbito nacional, a principal dificuldade é a precariedade de recursos materiais.

FIGURA 3: Dificuldades enfrentadas nas aulas que envolvem Educação Ambiental nas escolas de Educação Infantil e/ou Ensino Fundamental localizadas na Usina Trapiche (Sirinhaém/PE).

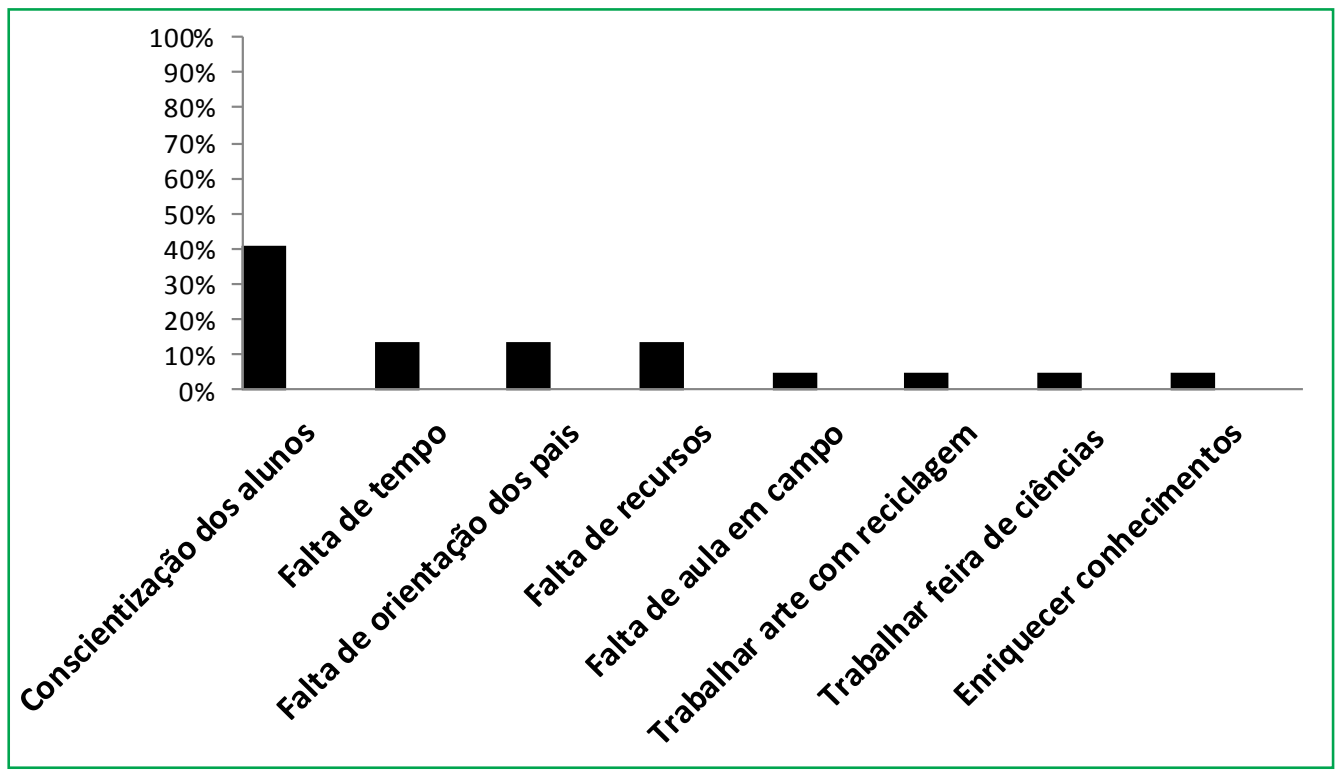


Quanto à disponibilidade de material (documentários, catálogos, etc.) oferecido pelas escolas aos alunos sobre a Mata Atlântica e seus ecossistemas associados, a maioria dos professores entrevistados considerou que os materiais oferecidos são suficientes.

Quanto à realização de atividades voltadas para a temática ambiental que envolva os pais dos alunos com a escola, $73 \%$ dos professores considerou que essa interação ocorre, pois alguns pais participam de atividades. Só não foi possível sabermos ao certo se essa participação se refere apenas à presença física ou se há um envolvimento mais efetivo, como, por exemplo, em decisões a serem tomadas. Veiga et al. (2005) observou que no Nordeste há uma menor interferência das escolas em atividades da comunidade. Loureiro et al. (2006) destacam a necessidade da escola de fortalecer seus vínculos com a comunidade e universidades, mas não podemos deixar de levar em consideração sua preocupação com as contradições existentes entre um discurso de participação e a construção efetiva de canais de diálogo e comunicação.

\section{Atividades realizadas nas escolas}

O referido projeto também incluiu atividades posteriores de extensão envolvendo os professores, alunos e outros integrantes da comunidade escolar.

Foram realizadas oficinas de reciclagem com produção de brinquedos, palestra sobre o estado de conservação da Mata Atlântica, jogos educativos, exposição e apresentação de uma peça teatral (outras atividades). Esse tipo de atividade lúdica foi escolhida devido a pouca idade dos alunos (Ensino Fundamental I).

As atividades de jogos e festas tratam e trabalham com os caracteres antagônicos do ser humano e possuem raízes que mergulham nas profundezas antropológicas; referindo-se ao ser humano em sua natureza (MORIN, 2000) Enquanto que Lopes (2000) menciona que o aprendizado se torna facilitado e com alta eficácia quando utiliza-se as atividades lúdicas.

A escolha dos temas foi baseada no contexto local, que se mostraram mais próximos dos indivíduos, e também nos temas gerais mais necessários de serem trabalhados, com destaque para a transformação da ideia de lixo como sendo algo que não serve mais.

As finalidades dessas atividades foram: sensibilizar os alunos para o entendimento da gravidade dos problemas ambientais e para que tivéssemos uma aceitação maior diante dos temas de EA abordados; incentivar a mudança de algumas práticas não sustentáveis, dentro e fora da escola, pelos diversos integrantes da comunidade escolar; fornecer aos professores novas condições metodológicas para o desenvolvimento de atividades e uma carga teórica mais profunda e atualizada; e aproximar os conhecimentos acadêmicos das escolas.

Os esforços para conservação ambiental devem estar atrelados à conscientização da população e para que isso ocorra, deve haver uma integração com o sistema educacional. Mesmo porque não é concebível uma formação básica do cidadão sem conscientização ambiental, da mesma forma que dificilmente teremos ações de conservação dos ambientes naturais realmente eficazes sem uma EA transformadora. A melhoria da formação do cidadão vai resultar em ações mais conscientes, individuais ou coletivas, e tudo isso passa necessariamente pela consolidação da EA. Novas concepções vão se convertendo em novas práticas, que vão necessitando de ajustes ao longo de sua experimentação, num processo dialético, que não ocorre do dia para a noite.

Observou-se que a EA está inserida em todas as escolas do presente estudo, mas, assim como visto por outros autores, ainda não há uma certeza de que as medidas adotadas são conscientes e se estão apontando para o melhor caminho de uma EA transformadora. De qualquer forma é interessante destacar o passo importante que representa a inserção da EA num novo contexto, que possivelmente está se formando, de relação entre o ser humano e o seu entorno, tendo em vista que a urgência de medidas que colaborem com a diminuição dos impactos na região até alcançarmos níveis sustentáveis.

As escolas estudadas deram um passo importante ao começar a desenvolver projetos com EA, acompanhando o crescimento dessa modalidade em todo o Brasil. Mas acreditamos que a modalidade de projetos não deva ser a única forma de aplicação da EA nas escolas. Esperamos 
que, com o tempo, a EA não seja um dos poucos temas que esteja dependendo da criação de projetos para serem abordados. Independente da forma de aplicação, o referido tema precisa ser inserido de tal forma que passe a fazer parte do cotidiano escolar.

Para isso, as intervenções são necessárias para ajudar a superar as dificuldades da EA. Fazendose necessário que as Universidades estejam mais próximas às escolas, tanto pela formação continuada para professores, quanto pela utilização da estrutura de pesquisa e extensão. É preciso fornecer um suporte técnico e teórico aos professores, assim como, aprofundar as discussões que levarão a comunidade escolar a direcionar o rumo de sua EA, de acordo com as necessidades sócio-ambientais locais.

\section{Agradecimentos}

À Pró-Reitoria de Extensão (PROEXT) da Universidade Federal de Pernambuco pelo financiamento concedido e a Usina Trapiche S.A. por permitir e apoiar a realização do presente estudo nas escolas.

\section{Referências}

BEZERrA, T. M. O.; FELICIANO, A. L. P.; AlVES, A. G. C. Percepção ambiental de alunos e professores do entorno da Estação Ecológica de Caetés - Região Metropolitana do Recife-PE. Biotemas, Florianópolis, v. 21, n. 1, p. 147-160, 2008.

BIONDO, E.; OLIVEIRA, E. C.; HARRES, J. B. S.; MARCHI, M. I. Dificuldades percebidas pelos professores da educação básica do Vale do Taquari/RS na aplicação de projetos de Educação Ambiental. Revista Educação Ambiental em Ação, Novo Hamburgo, n. 36, p 1-6. 2010.

BIZERRIL, M. X. A.; FARIA, D. S. Percepção de professores sobre a Educação Ambiental no ensino fundamental. Revista Brasileira de Estudos Pedagógicos, Brasília, v. 82, n. 200/201/202, p. 57-69, 2001.

BROOKS, T.; RYLANDS, A. B. Espécies no limiar da extinção: vertebrados terrestres criticamente em perigo. In: GALINDOLEAL, C.; CÂMARA, I. G. (Org.). Mata Atlântica: biodiversidade, ameaças e perspectivas. Belo Horizonte: Conservação Internacional, 2005. p. 360-371.

CAMPANILI, M.; PROCHNOW, M. Mata Atlântica, uma rede pela floresta. Brasília: RMA, 2006. 334 p.

CARVALHO, I. C. M. Em direção ao mundo da vida: interdisciplinaridade e educação ambiental. Cadernos de Educação Ambiental. Brasília: Instituto de Pesquisas Ecológicas, 1998. 102 p.

CARVALHO, I. C. M. Qual educação ambiental? Elementos para um debate sobre educação ambiental e extensão rural. Revista Agroecologia e Desenvolvimento Rural Sustentável, Porto Alegre, v. 2, n. 2, p. 43-51, 2001.

CARVALHO, I. C. M. A Educação Ambiental no Brasil. In: BRASIL (Ed.). Brasília: Ministério da Educação. Secretaria de Educação a Distância. Educação Ambiental no Brasil, 2008. p. 13-20.

DOURADO, L. Concepções e práticas dos professores de Ciências Naturais relativas à implementação integrada do trabalho laboratorial e do trabalho de campo. Revista Electrónica de Enseñanza de las Ciências, Vigo, v. 5, n. 1, p. 192-212, 2006.

EFFTING, R. T. Educação ambiental nas escolas públicas: realidade e desafios. 2007. 78 f. Monografia (Pós Graduação "Latu Sensu" em Planejamento Para o Desenvolvimento Sustentável) - Universidade Estadual do Oeste do Paraná, Marechal Cândido Rondon. 2007.

GALINDO-LEAL， C.; CÂMARA， I. G.; Mata Atlântica: biodiversidade, ameaças e perspectivas. São Paulo: Fundação SOS Mata Atlântica; Belo Horizonte: Conservação Internacional, 2005. $472 \mathrm{p}$.

GUERRA, A. F. S.; GUIMARÃES, M. Educação Ambiental no contexto escolar: questões levantadas no GDP. Pesquisa em Educação Ambiental, Ribeirão Preto, v. 2, n. 1 p. 155-166, 2007.

HERNÁNDEZ, F.; VENTURA, M. A. Organização do currículo por projetos de trabalho: o conhecimento é um caleidoscópio. 5 ed. Porto Alegre: Artmed, 2007.

JACOBI, P. Educação e meio ambiente - transformando as práticas. Revista Brasileira de Educação Ambiental, Brasília, n. 0, p. 1-140, 2004.

KRASILCHIK, M; MARANDINO, M. Ensino de ciências e cidadania. São Paulo: Moderna, 2004. 88 p.

LIMA, G. F. C. Questão ambiental e educação: contribuições para o debate. Ambiente \& Sociedade, Campinas, ano II, n. 5, p. 135 153, 1999.

LOPES, M. G. Jogos na educação: criar, fazer, jogar. 3 ed. São Paulo : Cortez, 2000.

LOUREIRO, C. F. B. Educar, participar e transformar em educação ambiental. Revista brasileira de educação ambiental, Brasília, $\mathrm{n}$. 0, p. 1-140, 2004.

LOUREIRO, C. F. B. Proposta Pedagógica. In: BRASIL (Ed.). Brasília: Ministério da Educação. Secretaria de Educação a Distância. Educação Ambiental no Brasil. 2008. p. 03-12.

LOUREIRO, C. F. B.; AMORIN, E. P.; AZEVEDO, L.; COSSÍO, M. B. Análise Nacional: conteúdos, gestão e percepção da educação ambiental nas escolas. In: TRAJBER, R.; MENDONÇA, P. R. (Org.). Educação na diversidade: o que fazem as escolas que dizem que fazem educação ambiental. Vol. 23, n. 6. Brasília: Secretaria de Educação Continuada, Alfabetização e Diversidade, Coleção Educação para Todos, Série Avaliação. 2006. p. 33-80.

MORELLATO, L.P.C.; HADDAD, C. F. B. Introduction: the Brazilian Atlantic Forest. Biotropica, Maiden, v. 32, n. 4, p. 786792, 2000.

MORIN, E. Os setes saberes necessários à educação do futuro. São Paulo: Cortez; Brasília: UNESCO, 2000.

QUINTAS, J. S. Educação no processo de gestão ambiental: uma proposta de educação ambiental transformadora e emancipatória. In: LAYRARGUES, P. P. (Coord.). Identidades da educação 
ambiental brasileira. Brasília: Ministério do Meio Ambiente, 2004. p. 113-140.

RANTA, P.; BLOM, T.; NIEMELA, J.; JOENSUU, E.; SIITONEN, $M$. The fragmented Atlantic rain forest of Brazil: size, shape and distribution of forest fragments. Biodiversity Conservation, Madrid, v. 7, n. 3, p. 385-403, 1998.

SANTOS, A. Complexidade e transdisciplinaridade em educação: cinco princípios para resgatar o elo perdido. Revista Brasileira de Educação, Campinas, v. 13, n. 37, p. 71-81, 2008.

SENICIATO, T.; CAVASSAN, O. Aulas de campo em ambientes naturais e aprendizagem em ciências - Um estudo com alunos do ensino fundamental. Ciência \& Educação, Bauru, v. 10, n. 1, p. 133-147, 2004.

SILVA, J. M. C.; TABARELLI, M. Tree species impoverishment and the future flora of the Atlantic Forest of Northeast Brazil. Nature, London, n. 404, p. 72-74, 2000.

TABARELLI, M.; PINTO, L. P.; SILVA, J. M. C.; HIROTA, M. M.; BEDÊ, L.C. 2005. Desafios e oportunidades para a Conservação da biodiversidade Na Mata Atlântica brasileira. Megadiversidade, Belo Horizonte, v. 1, n. 1, p. 132-138.
TOZONI-REIS, M. F. C. A inserção da educação ambiental na escola. In: BRASIL (Ed.). Brasília: Ministério da Educação. Secretaria de Educação a Distância. Educação Ambiental no Brasil, 2008. p. 46-53.

UCHOA-NETO, C. A. M.; TABARELLI, M. Diagnóstico e estratégia de conservação do centro de endemismo Pernambuco. Belém: Conservation International do Brasil, 2002. 69 p.

VEIGA, A.; AMORIN, E.; BLANCO, M. Um retrato da presença da Educação Ambiental no Ensino Fundamental Brasileiro: o percurso de um processo acelerado de expansão. Brasília: Instituto Nacional de Estudos e Pesquisas Educacionais Anísio Teixeira, 2005. $23 \mathrm{p}$.

VIANA, V. M.; TABANEZ A. A. J.; BATISTA, J. L. F. Dynamics and restoration of forest fragments in the Brazilian Atlantic moist Forest. In: LAURANCE, W. F.; BIERREGARD, R. O. (Ed.). Tropical forest remnants: ecology management and conservation of fragmented communities. Chicago: University of Chicago Press, 1997. p. 351-365. 